\title{
High-voltage Step-up Ratio Single-phase Three-wire Inverter Based on Interleaved Boost Converter
}

\author{
Tsair-Rong Chen, Yu-Lin Juan, Hsu-Ting Liu, Chun-Ming Chen, and Yu-Tzu Lee \\ National Changhua University of Education, No. 2, Shi-Da Road, Changhua City 500, Taiwan
}

(Received April 5, 2018; accepted May 28, 2018)

Keywords: coupled inductor, interleaved, single-phase three-wire inverter

A high-voltage step-up ratio inverter for applications using batteries as the input power source is proposed to supply the emergency power requirement from a battery pack when the grid is down. The proposed inverter is composed of an interleaved coupled-inductor boost converter and a three-leg full-bridge inverter. Four series-connected lead acid batteries are used as the input power source. When 110 and $220 \mathrm{~V} \mathrm{AC}$ outputs are required by the load sides at the same time, the $48 \mathrm{~V} \mathrm{DC}$ input from the batteries would be boosted up to $350 \mathrm{~V}$ DC for the three-leg inverter to provide AC output power. However, if only $110 \mathrm{~V}$ AC is required, the proposed control strategy would reduce the step-up ratio for a lower DC link voltage of $175 \mathrm{~V}$ DC to enhance the conversion efficiency. Moreover, to minimize damage to the batteries, the interleaved circuit topology is adopted to reduce the input current ripple. A prototype with 400 $\mathrm{W}$ rated output power is finally constructed. The controller is implemented with a low-cost microcontroller, HT66F50. From the experimental results, it is seen that even under unbalanced load conditions, the output AC voltage is well controlled. The total efficiency of the proposed inverter with $110 / 220 \mathrm{~V} \mathrm{AC}$ output is $89.8 \%$, and the efficiency of the inverter with only $110 \mathrm{~V}$ AC output is $91.1 \%$.

\section{Introduction}

To avoid power supply interruption in a remote area owing to natural disasters such as earthquake, typhoon, and debris flow, the emergency power supply system has attracted much attention in recent years. In the emergency power supply system, AC power of 110 and $220 \mathrm{~V}$ should be available for common electrical appliances and instruments. Gasoline/diesel engine generators or renewable energy sources are usually integrated into the power supply system. A battery pack is also required in the system for energy storage and buffer. In the most common system configuration, a $48 \mathrm{~V}$ battery pack with four series-connected batteries is used as the energy storage module. However, a DC input power with about 156 or $312 \mathrm{~V}$ is required for the conventional single-phase inverter to provide the 110 or $220 \mathrm{~V}$ AC output power, respectively. ${ }^{(1-4)}$ Therefore, a step-up DC converter would be required to boost the $48 \mathrm{~V}$ DC power up to at least 156 or $312 \mathrm{~V}$. Compared with the conventional boost converter, the coupled-inductor boost

*Corresponding author: e-mail: yljuan0815@cc.ncue.edu.tw

http://dx.doi.org/10.18494/SAM.2018.1956 
converter could more easily provide a high-voltage step-up ratio. ${ }^{(5-10)}$ However, the resulting current ripple in the low-voltage side would become higher than that in conventional topology, which would also result in additional power losses.

In this study, a high-voltage step-up ratio single-phase three-wire inverter is developed. A common $48 \mathrm{~V}$ battery pack is used as the input source in the proposed inverter. A two-phase coupled-inductor boost converter and a six-switch inverter are integrated into the proposed topology. The interleaved coupled-inductor boost converter would firstly convert the $48 \mathrm{~V}$ DC power into 175 or $350 \mathrm{~V}$ DC power for the six-switch inverter to properly provide 110 and $220 \mathrm{~V} \mathrm{AC}$ output power for the AC side load requirement. By adopting the interleaved circuit topology, the input current ripple can therefore be reduced. Moreover, the conduction power losses can also be reduced owing to the power sharing in the two-phase topology. ${ }^{(11-14)}$ As to the inverter, the sinusoidal pulse width modulation (PWM) mode is used to control the output $\mathrm{AC}$ voltage with 110 and $220 \mathrm{~V}$ rms. According to the loading demand, the output power can switch into only 110 or 110/220 V modes. A low-cost microcontroller unit, HT66F50, is used to realize the digital controller. The corresponding voltage and current signals are fed back to the microcontroller unit to control the DC link voltage as well as the output $\mathrm{AC}$ voltages.

\section{Circuit Topology and Operation Principles}

The configuration of the proposed inverter is shown in Fig. 1. A two-phase coupled-inductor boost converter and a six-switch inverter are integrated into the proposed inverter. By using the coupled inductor, the voltage step-up ratio of the boost converter can be enhanced. Moreover, the conversion efficiency can be enhanced by sharing the power with the adopted two-phase interleaved circuit topology. The $48 \mathrm{~V}$ DC voltage of the battery pack would therefore easily be boosted up to the required voltage level for the six-switch inverter. The high-side and lowside switches in one arm of the six-switch inverter are driven by a set of complementary PWM signals. For a single-phase three-wire AC output application, the output terminal V shown in Fig. 1 is controlled as the neutral line. The line voltages for loads $Z_{1}$ and $Z_{2}$ are regulated to $A C$ $110 \mathrm{~V}$ rms by adjusting the modulation index of the PWM gating signals of the switches $\mathrm{S}_{\mathrm{UH}}$, $\mathrm{S}_{\mathrm{WH}}, \mathrm{S}_{\mathrm{UL}}$, and $\mathrm{S}_{\mathrm{WL}}$.

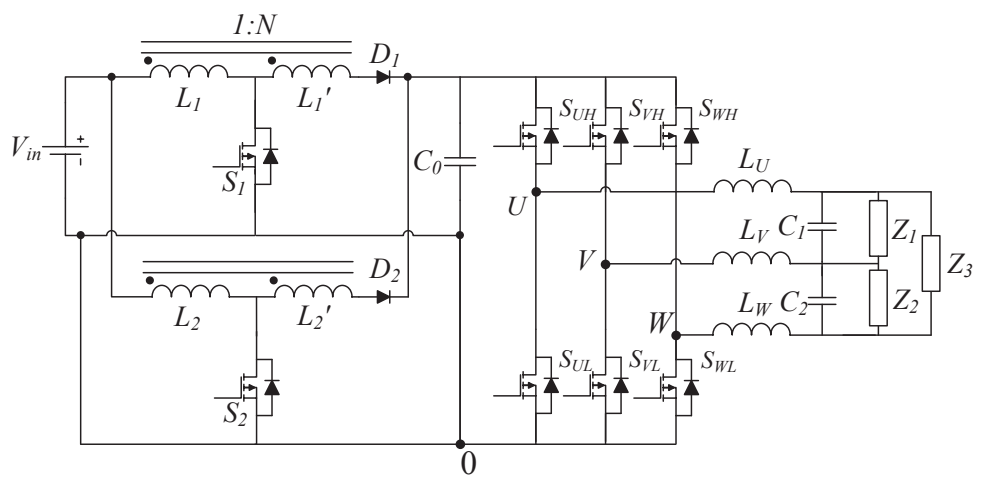

Fig. 1. Circuit configuration of the proposed inverter. 
The interleaved coupled-inductor boost converter is composed of two parallel-connected coupled-inductor boost converters as shown in Fig. 1. A set of gating signals with 180 degrees phase-shifted shown in Fig. 2 are used to control the two switches $S_{1}$ and $S_{2}$. The duty ratio of switches $\mathrm{S}_{1}$ and $\mathrm{S}_{2}$ are $d_{1}$ and $d_{2}$, respectively. It can be seen that the phase of the inductor current $i_{L 1}$ is also 180 degrees shifted with respect to that of the inductor current $i_{L 2}$. The output current of the battery pack noted as the total input current $i_{\text {in }}$ is the summation of the two inductor currents. Therefore, the current ripple of the battery pack output current would be reduced. As shown in Fig. 2, the $i_{L 1 m}$ and $i_{L 2 m}$ are the magnetizing currents of the coupled inductors $\mathrm{L}_{1}$ and $\mathrm{L}_{2}$, respectively. A lower current ripple would minimize damage to the battery pack as well.

The corresponding operation modes of the interleaved DC converter are shown in Fig. 3 and the operation principle in each mode is also described as follows.

- Mode $1\left(t_{0} \leq t<t_{1}\right)$ : Both switches $\mathrm{S}_{1}$ and $\mathrm{S}_{2}$ are turned on. The stored energy in the inductors $\mathrm{L}_{1}$ and $\mathrm{L}_{2}$ are increased by the input DC power source. The energy stored in the DC link capacitor $\mathrm{C}_{0}$ is released to the second-stage inverter.

- Mode $2\left(t_{1} \leq t<t_{2}\right)$ : The switch $\mathrm{S}_{1}$ is still turned on in this mode and the switch $\mathrm{S}_{2}$ is turned off. The diode $\mathrm{D}_{2}$ is then turned on for releasing the energy from the inductor $\mathrm{L}_{2}$ to the $\mathrm{DC}$ link. The equivalent model of the coupled inductor is shown in Fig. 4. It is seen that the

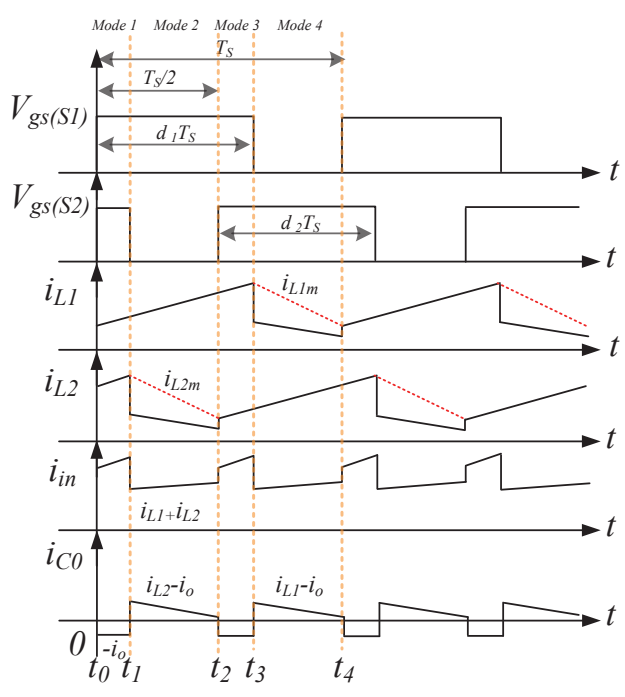

Fig. 2. (Color online) Relative waveforms of the interleaved boost converter.
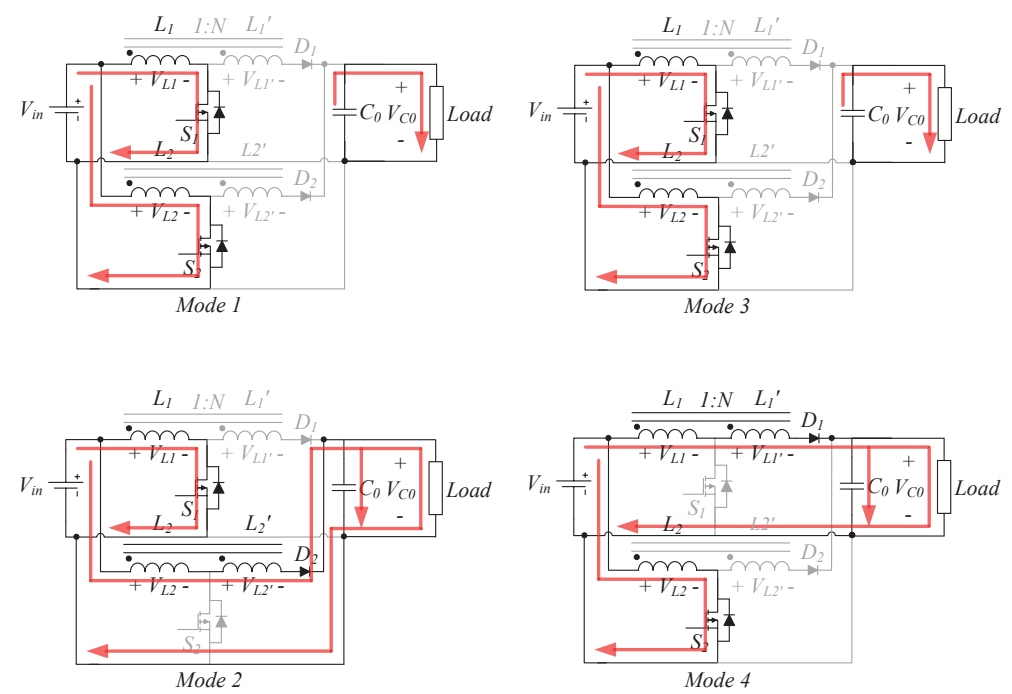

Fig. 3. (Color online) Operation modes of the interleaved-coupled inductor boost converter.

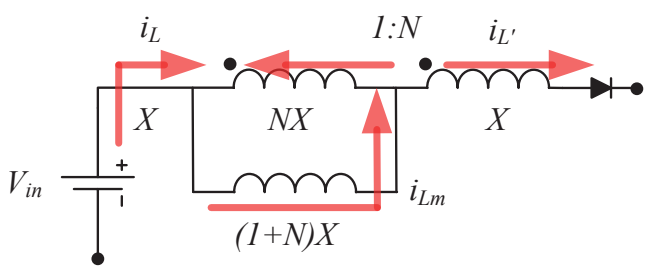

Fig. 4. (Color online) Equivalent model of the coupled inductor. 
current through diode $\mathrm{D}_{2}$ would be expressed as $i_{L 2 m} \times[1 /(N+1)]$, where $N$ is the turn ratio.

- Mode $3\left(t_{2} \leq t<t_{3}\right)$ : In this mode, the switch $\mathrm{S}_{2}$ would be turned on again. Therefore, the operation principle of this mode is similar to that of mode 1 .

- Mode $4\left(t_{3} \leq t<t_{4}\right)$ : The switch $\mathrm{S}_{1}$ is turned off in this mode, then diode $\mathrm{D}_{1}$ would be turned on to release the energy from the inductor $\mathrm{L}_{1}$ to the DC link. The currents in the coupled inductor $\mathrm{L}_{1}$ are similar to those in the coupled inductor $\mathrm{L}_{2}$ in mode 2. The current of $\mathrm{D}_{1}$ would be $i_{L 1 m} \times[1 /(N+1)]$.

To ensure that the converter is operated under continuous conduction mode, the secondary side current of each coupled inductor should not be reduced to zero. As shown in Fig. 5, the design criteria of the inductor can then be derived as Eqs. (1) to (4). Moreover, the peak value of each phase input current can also be derived as Eq. (5).

$$
\begin{gathered}
\frac{1}{2}\left(\Delta i_{L^{\prime}}+2 a\right)(1-D) T_{S}=\frac{V_{o}}{2 R_{L}} T_{S} \\
\Delta i_{L^{\prime}}=\frac{d i_{L 2^{\prime}}}{d t}(1-D) T_{S} \\
a=\frac{V_{o}}{2(1-D) R_{L}}+\frac{V_{\text {in }}-V_{o}}{2(N+1)^{2} L}(1-D) T_{S} \\
L_{1,2} \geq \frac{\left(V_{o}-V_{\text {in }}\right)(1-D)^{2} R_{L} T_{S}}{(N+1)^{2} V_{o}} \\
i_{L p}=i_{L m p}=(N+1)\left[\frac{V_{o}}{2(1-D) R_{L}}+\frac{\left(V_{o}-V_{\text {in }}\right)(1-D) T_{S}}{2(N+1)^{2} L}\right]
\end{gathered}
$$

As to the six-switch inverter, there are two operation modes proposed in this study according to the AC side load requirement. While the AC $220 \mathrm{~V}$ rms output power is required, the sixswitch inverter would be operated in mode A. Otherwise, when only $110 \mathrm{~V} \mathrm{rms}$ is demanded at the load terminals, the six-switch inverter would be operated in mode B to reduce the DC link voltage. Hence, the voltage step-ratio requirement of the interleaved coupled-inductor boost converter can be reduced to enhance the conversion efficiency. ${ }^{(15)}$ The PWM profiles for the proposed two operation modes are shown in Fig. 6 and the corresponding principles are described as follows.

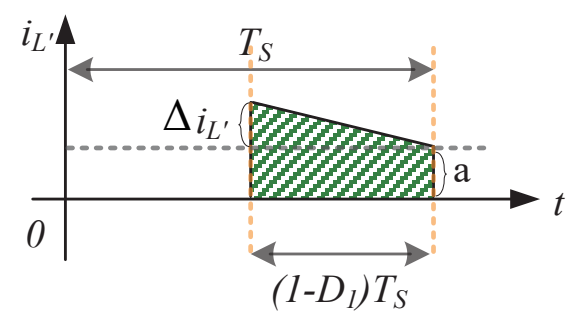

Fig. 5. (Color online) Current of the diode in the boost converter. 


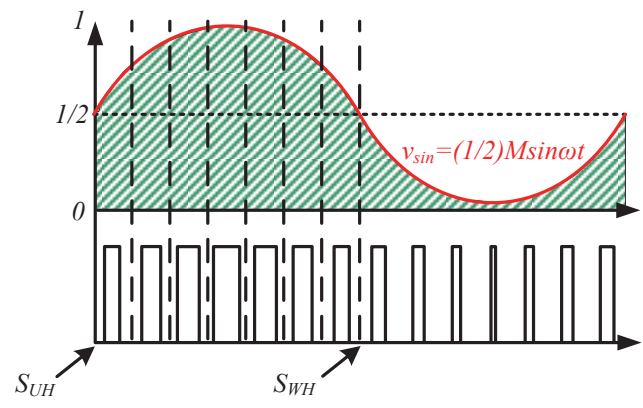

(a)

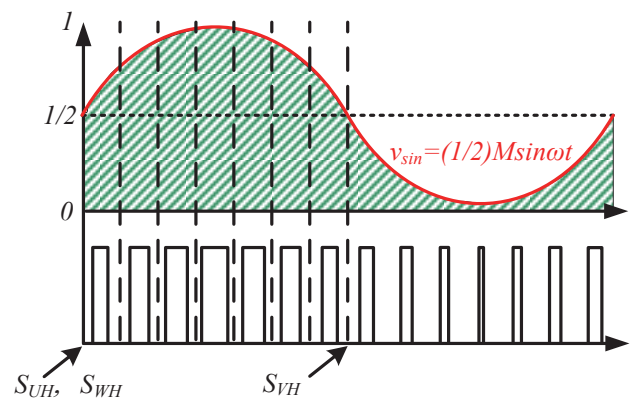

(b)

Fig. 6. (Color online) Switching patterns in operation (a) mode A and (b) mode B.

- Mode A:

In this mode, the DC link voltage is boosted up to $350 \mathrm{~V}$ for the six-switch inverter to generate 220 and $110 \mathrm{~V}$ rms AC voltage at the load sides. The phase $\mathrm{V}$ is controlled to be the neutral line of the single-phase three-wire 110/220 V AC output application. The two legs ( $\mathrm{S}_{\mathrm{UH}}$, $\mathrm{S}_{\mathrm{UL}}$ and $\mathrm{S}_{\mathrm{WH}}, \mathrm{S}_{\mathrm{WL}}$ ) are controlled by a set of sinusoidal PWM signals with a phase difference of 180 degrees as shown in Fig. 6(a). It is seen that the control signal of $\mathrm{S}_{\mathrm{WH}}$ is 180 degrees lagged with respect to that of $\mathrm{S}_{\mathrm{UH}}$. Two switches on the same leg are switched by a set of complementary gating signals.

\section{- Mode B:}

In this mode, there is only $110 \mathrm{~V}$ AC voltage required at the load sides. The switching patterns for the arms are shown in Fig. 6(b). The phase V controlled by switches $S_{V H}$ and $S_{V L}$ is no longer controlled to be the neutral line. The switches $\mathrm{S}_{\mathrm{UH}}$ and $\mathrm{S}_{\mathrm{WH}}$ are controlled by the same PWM signal, and the control signal of $\mathrm{S}_{\mathrm{VH}}$ is 180 degrees lagged with respect to that of $\mathrm{S}_{\mathrm{UH}}$ and $\mathrm{S}_{\mathrm{WH}}$ in this mode. Therefore, there would be two $110 \mathrm{~V}$ AC outputs of $V_{U V}$ and $V_{V W}$ with 180 degrees phase difference. As a result, the DC link voltage is only boosted up to $175 \mathrm{~V}$.

\section{Controller Diagram of Proposed Inverter}

There are two control objectives in operating the proposed inverter. Firstly, according to the load demand at the AC output terminals, the DC link voltage would be regulated to 350 or $175 \mathrm{~V}$ with respect to the operation mode A or mode B. The DC link voltage and two inductor currents of the two-phase boost converter are sensed and fed back to the microcontroller unit as shown in Fig. 7. Secondly, the sinusoidal PWM signals in the corresponding operation modes illustrated in Sect. 2 would be generated by the microcontroller unit to control the six switches in the three-arm inverter. The corresponding control block diagrams of mode A and mode B are shown in Figs. 8 and 9, respectively.

As shown in Fig. 7, the DC link voltage of the capacitor $\mathrm{C}_{0}$ is denoted as $V_{C 0}$ and the inductor currents of inductors $\mathrm{L}_{1}$ and $\mathrm{L}_{2}$ are denoted as $I_{L 1}$ and $I_{L 2}$, respectively. The command of the total input current, namely, $I_{L}$ command, is obtained from the PI controller in the voltage control loop. The command of the DC link voltage $V_{C 0}{ }^{*}$ is set to $350 \mathrm{~V}$ for operation mode A or $175 \mathrm{~V}$ for mode B. Then, the current command for each inductor current in the two-phase converter is 


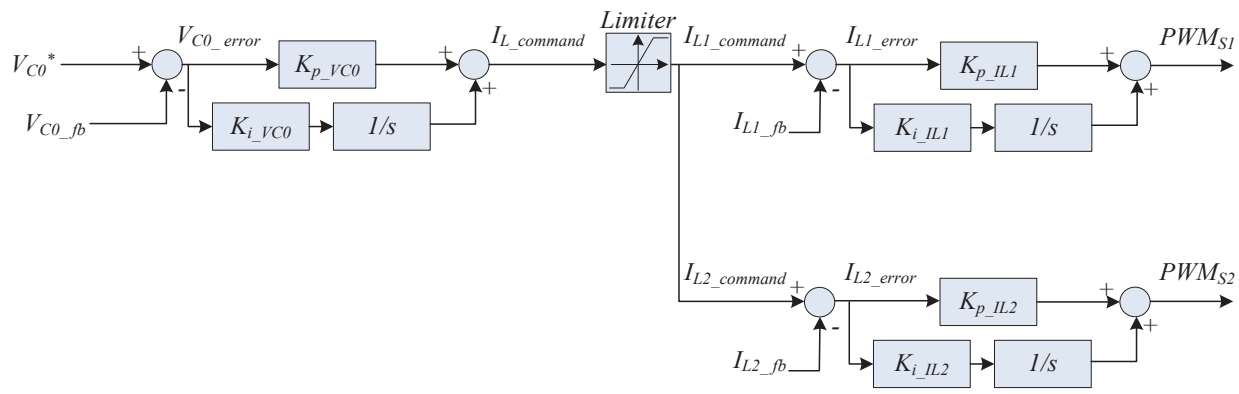

Fig. 7. (Color online) Control block diagram of the interleaved boost converter.
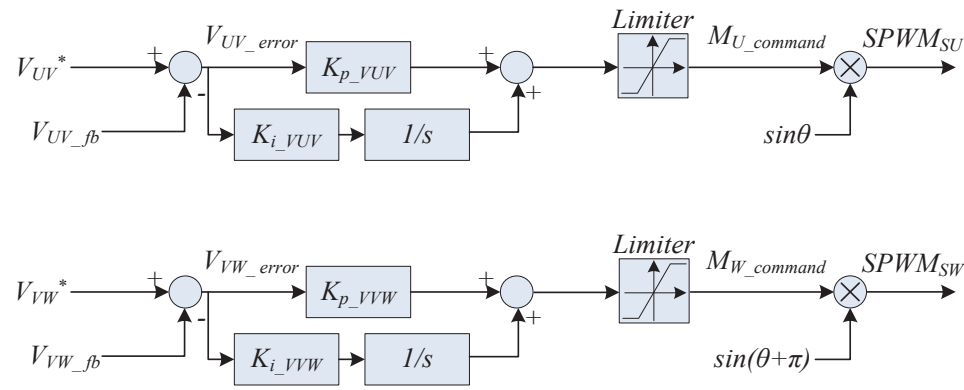

Fig. 8. (Color online) Control block diagram of operation mode A.
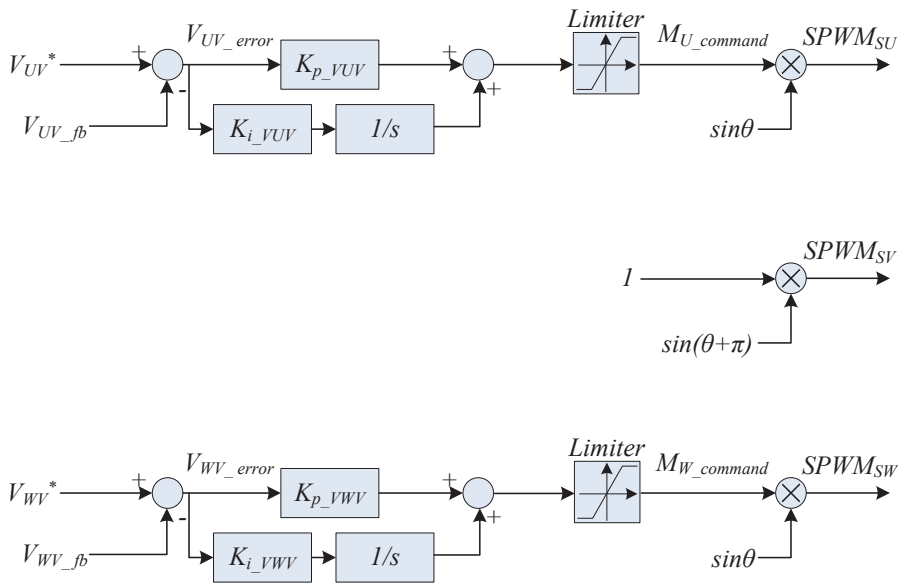

Fig. 9. (Color online) Control block diagram of operation mode B.

equal to the command $I_{L_{-} \text {command }}$ for sharing the power flow. As a result, the PWM signals for switches $S_{1}$ and $S_{2}$ would be generated accordingly.

For the control block diagram for operation mode $\mathrm{A}$ as shown in Fig. 8 , the line voltage $V_{U V}$ for load $\mathrm{Z}_{1}$ would be $110 \mathrm{~V}$ rms and 180 degrees phase-shifted with respect to the line voltage $V_{V W}$ for load $\mathrm{Z}_{2}$. Therefore, the line voltage $V_{U W}$ for load $\mathrm{Z}_{3}$ would be $220 \mathrm{~V}$ rms, which is the summation of $V_{U V}$ and $V_{V W}$. It can be seen that the phase difference between the modulation indexes of the PWM signals for switches $\mathrm{S}_{\mathrm{UH}}$ and $\mathrm{S}_{\mathrm{WH}}$ is 180 degrees. The PWM signals of switches $S_{U L}$ and $S_{W L}$ are complementary to that of switches $S_{U H}$ and $S_{W H}$, respectively. The 
peak values of the two AC output voltages are fed back and denoted as $V_{U V_{f} f b}$ and $V_{V W_{-} f b}$. Then, the corresponding modulation index required for the amplitude control of each AC output voltage would be calculated using the proportion-integration (PI) controller. In this mode, the output terminal V should be the controller to be the neutral node. Hence, a set of complementary PWM signals with 50\% duty ratio are used to control switches $\mathrm{S}_{\mathrm{VH}}$ and $\mathrm{S}_{\mathrm{VL}}$.

Figure 9 shows the control block diagram of mode B. The modulation indexes for switches $\mathrm{S}_{\mathrm{UH}}$ and $\mathrm{S}_{\mathrm{WH}}$ are in phase to each other. A sinusoidal PWM signal with 180 degrees phase lag is adopted to control the switch $\mathrm{S}_{\mathrm{VH}}$ in this mode. As a result, only two $110 \mathrm{~V}$ rms voltages would be provided at the output terminals and the required DC link voltage would be twice lower than that in mode A. The step-up ratio of the converter can therefore be reduced to enhance the conversion efficiency.

\section{Experimental Results}

Figure 10 shows the constructed prototype of the proposed high-voltage step-up ratio singlephase three-wire inverter. The corresponding circuit parameters of the constructed hardware are shown in Table 1. Figure 11 shows the measured waveforms of the control signals of

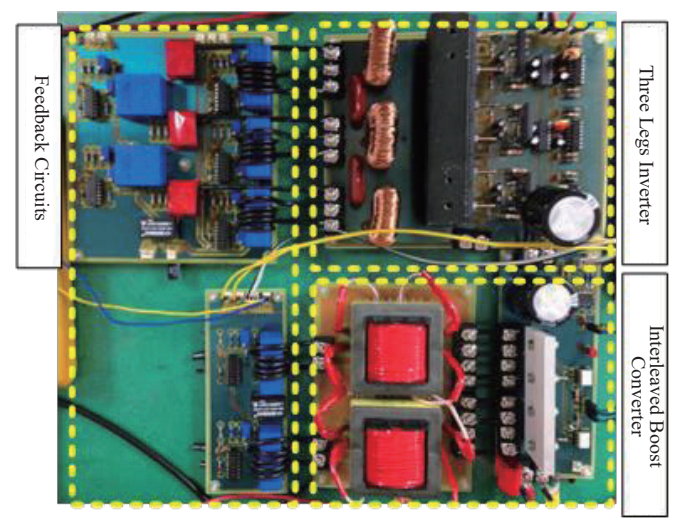

Fig. 10. (Color online) Constructed prototype of proposed inverter.

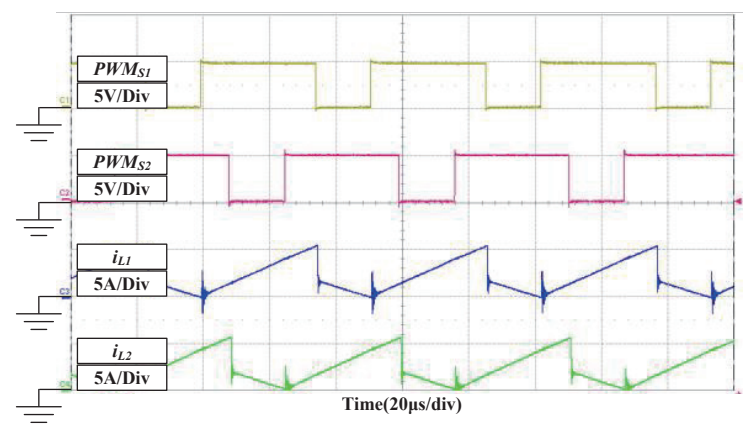

Fig. 11. (Color online) Relative input waveforms of the proposed inverter.

Table 1

Circuit parameters.

\begin{tabular}{lc}
\hline Rated power & $400 \mathrm{~W}$ \\
Lead-acid batteries & $12 \mathrm{~V} / 22 \mathrm{AH}$ \\
Switching frequency & $19.53 \mathrm{kHz}$ \\
Primary side inductor $\mathrm{L}_{1}, \mathrm{~L}_{2}$ & $300 \mu \mathrm{H}$ \\
Secondary side inductor $\mathrm{L}_{1}, \mathrm{~L}_{2}$, & $1200 \mu \mathrm{H}$ \\
DC link capacitor $\mathrm{C}_{0}$ & $470 \mu \mathrm{F} / 400 \mathrm{~V}$ \\
DC link voltage & $350 / 175 \mathrm{~V}$ \\
AC output inductor $\mathrm{L}_{\mathrm{U}}, \mathrm{L}_{\mathrm{V}}, \mathrm{L}_{\mathrm{W}}$ & $2 \mathrm{mH}$ \\
AC output capacitor $\mathrm{C}_{1}, \mathrm{C}_{2}$ & $6.6 \mu \mathrm{F}$ \\
Output AC voltage & $110 / 220 \mathrm{~V}$ \\
\hline
\end{tabular}


switches $\mathrm{S}_{1}$ and $\mathrm{S}_{2}$ and the inductor currents $i_{L 1}$ and $i_{L 2}$. The control signals of switches $\mathrm{S}_{1}$ and $\mathrm{S}_{2}$ are interleaved by 180 degrees. The total input current from the battery tank is shown in Fig. 12. It can be seen that the ripple on the input current is greatly reduced. The input voltage $48 \mathrm{~V}$ DC is boosted up to $350 \mathrm{~V}$ while providing $400 \mathrm{~W}$ power to the DC link, where $I_{o}$ is the output current to the DC link. The reduced current ripple on the battery output current would also reduce the loss caused by the equivalent resistance in the battery and prevent additional damage to the battery.

The efficiency comparison between the adopted two-phase interleaved boost converter and the conventional single-phase boost converter with $400 \mathrm{~W}$ rated output power is shown in Fig. 13. In the operation under light to half load, the efficiency of the interleaved converter is about $3 \%$ higher. As to the heavy load condition, the interleaved topology can provide even higher efficiency of about $4 \%$, which is because of the higher conduction losses in the single-phase boost converter.

Figure 14 shows the output waveforms while the inverter is operated under mode $\mathrm{A}$ as mentioned in the previous section. The inverter provided $50 \mathrm{~W}$ to load $\mathrm{Z}_{1}$ and $350 \mathrm{~W}$ to load $Z_{2}$. It seems that there is no difference between the two output voltages on the loads $Z_{1}$ and $Z_{2}$, i.e., $V_{U V}$ and $V_{V W}$. The results of the inverter operated under mode $\mathrm{B}$ are shown in Fig. 15. The total output is $400 \mathrm{~W}$, which is $200 \mathrm{~W}$ for load $Z_{1}$ and $200 \mathrm{~W}$ for load $Z_{2}$. The total efficiency of the proposed inverter is shown in Fig. 16. It can be seen that the efficiency of the proposed topology would be better because the proposed controller can change the operation mode into

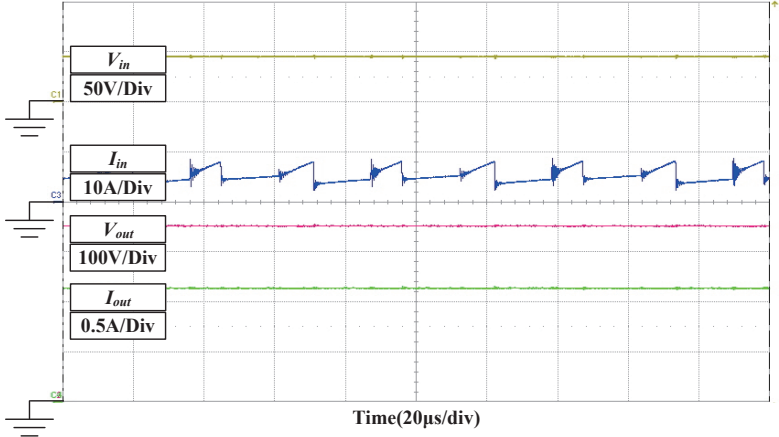

Fig. 12. (Color online) Waveforms of input voltage/ current and output voltage/current of the interleaved boost converter.

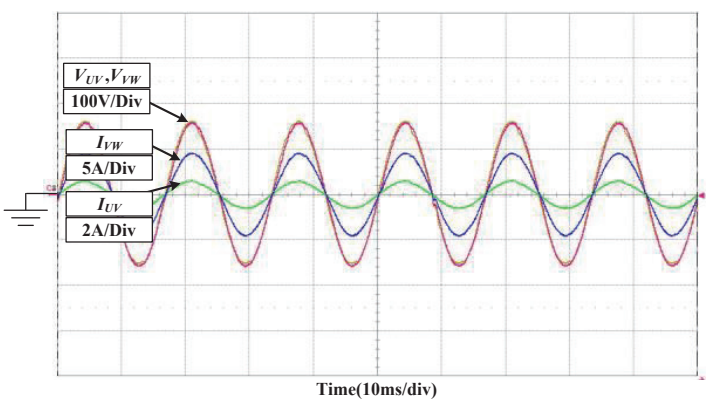

Fig. 14. (Color online) Output waveforms of the inverter under operation mode A.

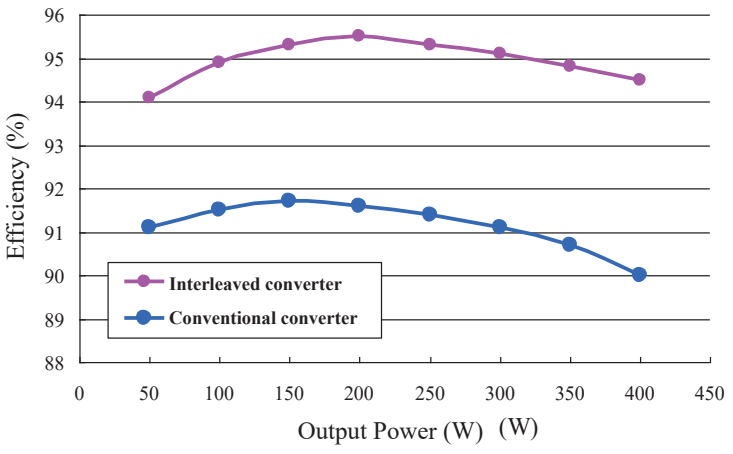

Fig. 13. (Color online) Efficiency comparison between interleaved and conventional converters.

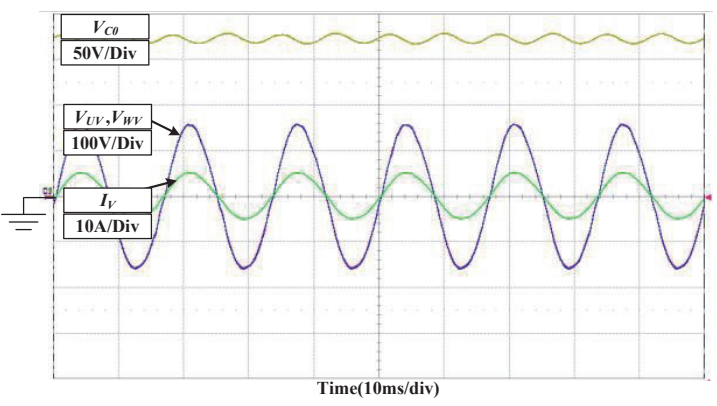

Fig. 15. (Color online) Output waveforms of the inverter under operation mode B. 


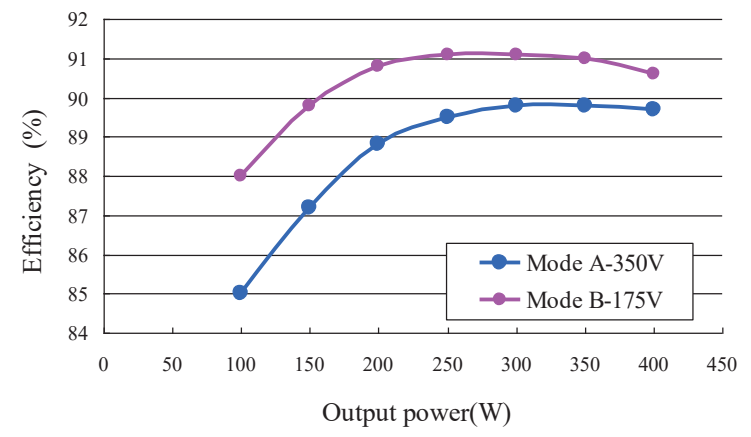

Fig. 16. (Color online) Total efficiency of the proposed inverter in different modes.

mode $\mathrm{B}$ while there is only $110 \mathrm{~V}$ AC load demand, and the $\mathrm{DC}$ link is only required to be boosted up to $175 \mathrm{~V}$ DC.

\section{Conclusions}

In this study, a high-voltage step-up ratio single-phase three-wire inverter is proposed for providing emergency power from a battery pack. By adopting the coupled inductor, the voltage step-up ratio was increased for boosting the battery pack terminal voltage to the required level. Furthermore, an additional control strategy for the inverter with only $110 \mathrm{~V}$ AC loading demand is proposed. In this operation mode, the voltage step-up ratio would be only half of that in the normal operation mode with 110 and $220 \mathrm{~V}$ output power. The lower voltage step-up ratio would therefore increase the conversion efficiency. From the experimental results, the proposed inverter can provide good efficiency higher than $90 \%$ and up to about $91.6 \%$ while only $110 \mathrm{~V}$ $\mathrm{AC}$ is required at the load side. The efficiency can also remain up to about $89.8 \%$ while the 220 $\mathrm{V}$ AC is required. The experiments with unbalanced load between two output AC ports are also carried out to verify that the proposed inverter can still provide stable 110 and $220 \mathrm{~V}$ AC output power.

\section{Acknowledgments}

This work was supported in part by the Ministry of Science and Technology, R.O.C., under Grant Nos. MOST 105-2221-E-018-014-MY3 and MOST 106-2221-E-018-016.

\section{References}

1 X. Zhang, L. Jiang, J. Deng, S. Li, and Z. Chen: IEEE Trans. Power Electron. 8 (2014) 4270.

2 T. Tanaka, T. Sekiya, H. Tanaka, M. Okamoto, and E. Hiraki: IEEE Trans. Ind. Appl. 6 (2013) 2628.

3 J. Loncarski, M. Leijon, M. Srndovic, C. Rossi, and G. Grandi: Energies 5 (2015) 3832.

4 F. J. Lin, H. C. Chiang, and J. K. Chang: Energies 12 (2016) 993.

5 S. M. Chen, T. J. Liang, L. S. Yang, and J. F. Chen: IEEE Trans. Power Electron. 4 (2012) 1809.

6 Y. Zhao, W. Li, and X. He: IEEE Trans. Power Electron. 6 (2012) 2869.

7 J. M. Shen, H. L. Jou, and J. C. Wu: IET Power Electron. 9 (2012) 1847.

8 L. Y. Chang, J. H. Chang, K. H. Chao, and Y. N. Chung: Energies 10 (2016) 792.

9 Y. T. Chen, W. C. Lin, and R. H. Liang: Int. J. Circuit Theory Appl. 43 (2014) 967.

10 T. V. Nguyen, P. Petit, M. Aillerie, C. Salame, and J. P. Charles: Int. J. Circuit Theory Appl. 43 (2014) 1042.

11 W. Li, X. He, D. Xu, and B. Wu: IEEE Trans. Ind. Electron. 3 (2012) 1650. 
12 W. Li, X. Xiang, C. Li, W. Li, and X. He: IEEE Trans. Power Electron. 1 (2013) 300.

13 B. C. Barry, J. G. Hayes, and M. S. Ryłko: IEEE Trans. Power Electron. 12 (2015) 6551.

14 C. L. Shen, P. C. Chiu, and Y. C. Lee: Energies 11 (2016) 871.

15 R. W. Erickson and D. Maksimovic: Fundamentals of Power Electronics (Springer, New York, 2000) 2nd ed.

\section{About the Authors}

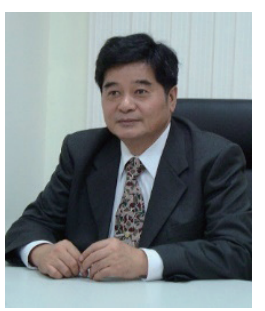

Tsair-Rong Chen was born in Taichung, Taiwan, R.O.C., in $1956 . \mathrm{He}$ graduated in 1986 from National Chen Kung University, Taiwan, with a B.S. degree and in 1988 with an M. S. degree, majoring in electrical engineering. Afterward, he attended National Sun Yat-sen University, Taiwan, to receive a Ph.D. degree in 1991 majoring in electrical engineering. He is a distinguished professor in the Department of Electrical Engineering, National Changhua University of Education, Taiwan.

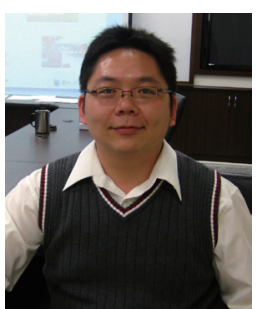

Yu-Lin Juan was born in Kaohsiung, Taiwan, R.O.C., in 1979. He graduated in 2001 from National Chen Kung University, Taiwan, with a B.S. degree in electrical engineering. Afterward, he attended National Tsing Hua University, Taiwan, to receive an M.S. degree in 2003 and a Ph.D. degree in 2010, majoring in electrical engineering. $\mathrm{He}$ is an associate professor in the Department of Electrical Engineering, National Changhua University of Education, Taiwan.

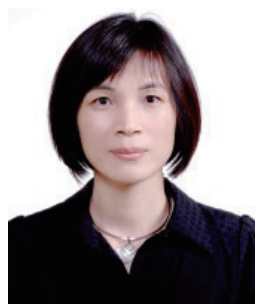

Hsu-Ting Liu was born in Changhua, Taiwan, R.O.C., in 1966. She graduated in 2013 from National Changhua University of Education, Taiwan, with an M.S. degree in electrical engineering. Currently, she is a Ph.D. student of the Department of Electrical Engineering, National Changhua University of Education, Taiwan.

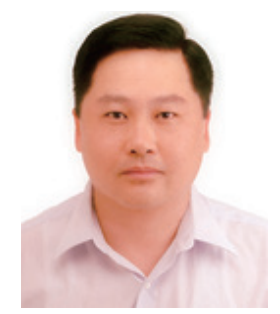

Chun-Ming Chen was born in Taichung, Taiwan, R.O.C., in 1963. He majored in electrical engineering and graduated in 1989 from National Taipei Industrial College. With enthusiasm and work experience at power stations, he started studying in National Changhua University of Education, Taiwan to receive an M.S. degree in 2009 and kept on studying for a Ph.D. degree majoring in electrical engineering. He had work experience in Gibsin Engineers Ltd., and his professional experience is on the construction of traditional power stations as well as wind farms and solar farms.

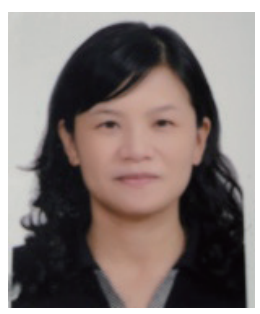

Yu-Tzu Lee was born in Changhua, Taiwan, R.O.C., in 1970. She started studying in National Changhua University of Education, Taiwan, to receive an M.S. degree in 2013 and kept on studying for a Ph.D. degree majoring in electrical engineering. She had work experience in a cram school, and her research interests are in education and radio frequency identifier (RFID) applications. 